\title{
Correction to: Policy uncertainty, derivatives use, and firm-level FDI
}

Quang Nguyen ${ }^{1}$, Trang Kim² and Marina Papanastassiou ${ }^{1}$

\footnotetext{
${ }^{1}$ Business School, Middlesex University, London NW4 4BT, UK; ${ }^{2}$ Faculty of Banking and Finance, Foreign Trade University, 91 Chua Lang ST, Dong Da Dist, Hanoi, Vietnam
}

\section{Correspondence:}

Q Nguyen, Business School, Middlesex University, London NW4 4BT, UK.

Tel: +(44)07475081518;

Fax: +(44)(0)20 84116607 ;

e-mail: Q.Nguyen@mdx.ac.uk
Journal of International Business Studies (2018) 49, 248.

https://doi.org/ | 0.1057/s4 1267-017-0124-6

\section{CORRECTION TO: JOURNAL OF INTERNATIONAL BUSINESS STUDIES (2017). \\ https://doi:10.1057/s41267-017-0090-z}

Since this paper was first published, the publisher has been informed of an additional contributing author that should have been included. The authorship has now been corrected online, and the author's biographical sketch has been added. No other changes have been made to the text. 